\title{
Internet of Thing Technology Concentration for Reliable and Smart Power System
}

\author{
Hnin Yi Aye \\ IT Department, \\ West Yangon Technological University, \\ Myanmar
}

\author{
Ohn Zin Lin \\ Electrical Power Department, \\ Yangon Technological University, \\ Myanmar
}

\begin{abstract}
Internet of Thing becomes a advanced technology in transforming many areas of mod-ern age including power system. Electricity is also a backbone of the country's economy and it is important to get the reliable supply at all time. Using IoT technology, the switching time and restoration of the system can be reduced and consequently the reliability can be improved. In this paper, how to concern the IoT technology in power system is described. Moreover, the reliability improvement by IoT technology is also conducted with the reliability indices analysis. According to the results, the amount of energy not supply, ENS and system average interruption duration is reduced by the IoT technology. The reliability test system of RBTS bus 2 is used as the test system.
\end{abstract}

Keywords: I0T, Power system, Reliability improvement, Energy not supply, SAIDI, Smart Grid

\section{INTRODUCTION}

The Internet of Things (IoT) refers to the use of intelligently connected devices and systems to leverage data gathered by embedded sensors and actuators in machines and other physical objects. IoT is expected to spread rapidly over the coming years and this convergence will unleash a new dimension of services that improve the quality of life of consumers and productivity of enterprises, unlocking an opportunity. For consumers, the IoT has the potential to deliver solutions that dramatically improve energy efficiency, security, health, education and many other aspects of daily life. For enterprises, IoT can under-pin solutions that improve decision-making and productivity in manufacturing, retail, agriculture and other sectors [1].

.The major area where IoT deals with energy management systems is the smart grid. IOT extends the benefits of smart grid be-yond the automation, distribution and monitoring being done by the utilities [2]. The task of the IoT in the field of electrical energy includes

(1) Advanced Metering Infrastructure (AMI)

(2) SCADA (Supervisory Control and Data Acquisition)

(3) Smart Inverters

(4) Remote control operation of energy consuming devices

By using conventional switch gears in distribution systems, it takes too much time to know fault locations and to disconnect the faulted lines. By using Distribution Automation System (DAS), the problem can be solved in short time. . Therefore, it is necessary to use automated protections devices controlled by SCADA system to improve the reliability of the system. And IOT technology is used in SCADA system.

In SCADA system, Remote Telemetry Unit (RTU) is a device that collects and transmits the data to Mater Terminal Unit (MTU). RTUs are equipped with input chan-nels for sensing or metering, output channels for control. A block diagram of RTU is shown in Fig.1. The working principle of each protection devices such as disconnector and circuit breaker (CB) are monitored by programmable logic controller (PLC)[3].

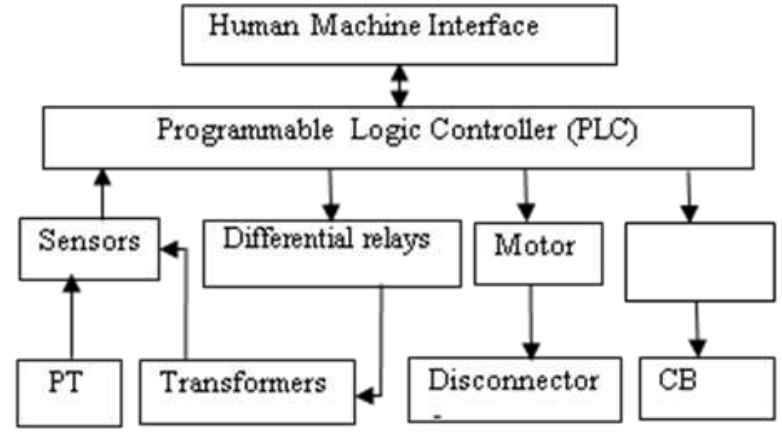

Fig. 1 Block Diagram of RTU

\section{METHODOLOGY}

Distribution system is responsible for transferring electrical energy to the end users. The outage in the distribution system has a localized effect compared with generation and transmission sectors. However, analysis of the customer failure statistics indicates that the distribution system has the greatest contribution to the unavailability of supply to a customer.

In this paper, to analyze the impact of protection system on reliability, following reliability indices are used: system average interruption frequency index (SAIFI), system average interruption duration index (SAIDI), customer average interruption duration index (CAIDI), energy not supplied index (ENS) and average energy not supplied index (AENS) The equations of reliability indices are equation (1)-(5) [4].

Reliability indices are typically computed by utilities at the end of each year by using historical outage data recorded in distribution outage reports. This is important because utilities know how their systems are performing. However, it is less useful when the specific impact of various design improvement options wish to be quantified and compared. To make such comparisons, a model must be developed which is capable of predicting.

SAIFI $=\frac{\text { total number } \text { of customer interrupti ons }}{\text { total number of customer sserved }}$ 


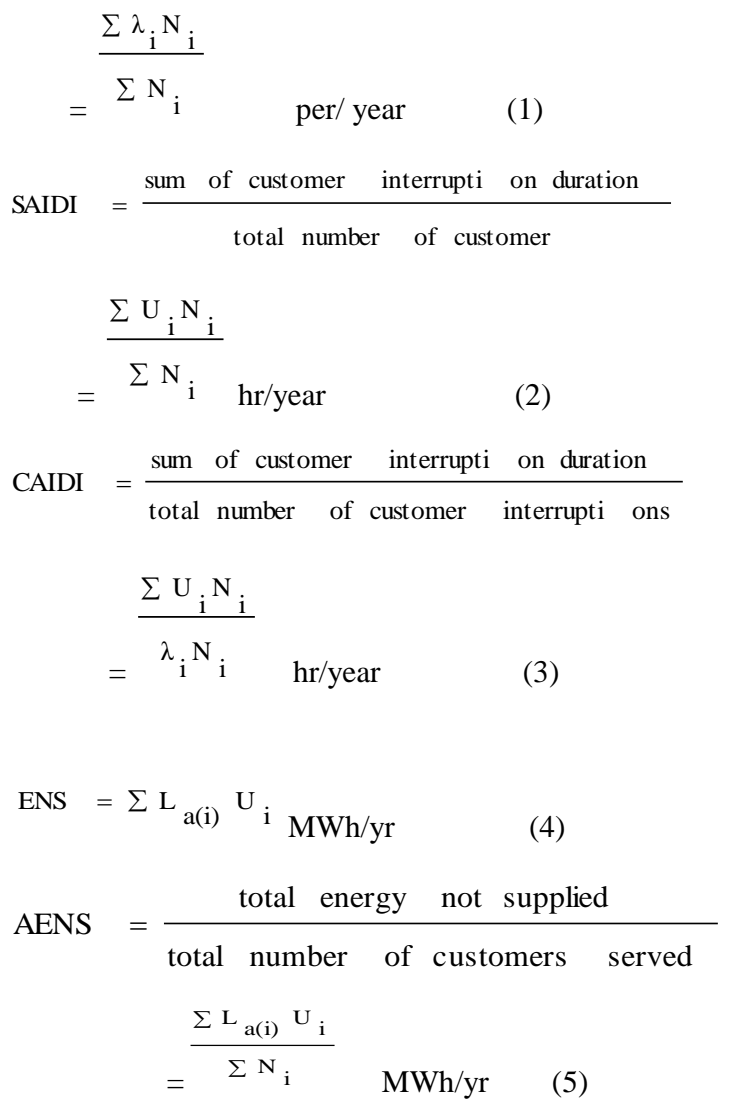

ENS $=\sum \mathrm{L}_{\text {a(i) }} \mathrm{U}_{\mathrm{i}} \mathrm{MWh} / \mathrm{yr}$

AENS

$=\frac{\text { total energy not supplied }}{\text { total number of customers served }}$
$=\frac{\sum \mathrm{L}_{\mathrm{a}(\mathrm{i})} \mathrm{U}_{\mathrm{i}}}{\sum \mathrm{N}_{\mathrm{i}}} \mathrm{MWh} / \mathrm{yr}$

Where $\mathbf{L}_{\mathbf{a}(\mathbf{i})}$ is average load demand at load point $\mathbf{i}$ and $\mathbf{U}_{\mathbf{i}}$ is outage time at load point $\mathbf{i}$.

Reliability indices are useful for determining what a customer can expect in terms of interruption frequencies and durations [4].

\section{TEST SYSTEM AND DATA}

The test system used in this paper is RBTS Bus 2 system shown in Figure 2 [5]. The single $11 \mathrm{kV}$ supply point for RBTS Bus 2 system is justified by the $20 \mathrm{MW}$ load. The feeders are operated as radial feeders alt-hough they can be connected as a mesh through normally open sectionalizing points.

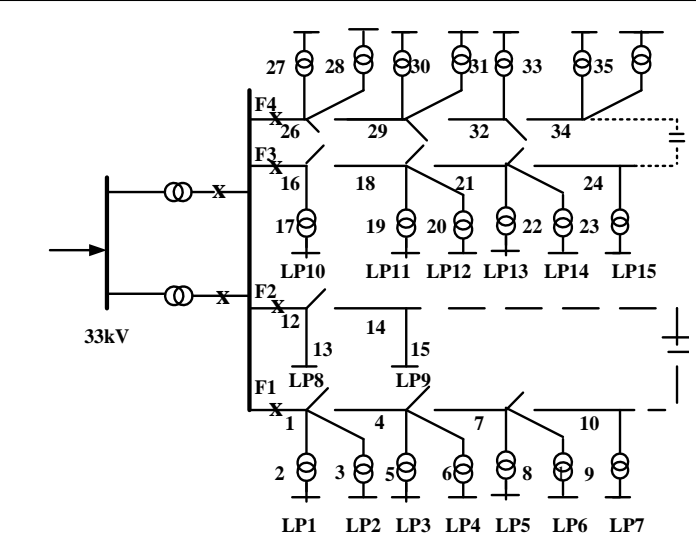

Fig. 2 Distribution system for RBTS bus 2
Table 1 Feeder types and lengths

\begin{tabular}{|l|l|l|}
\hline $\begin{array}{l}\text { Feeder } \\
\text { Type }\end{array}$ & $\begin{array}{l}\text { Length } \\
(\mathrm{km})\end{array}$ & $\begin{array}{l}\text { Feeder section } \\
\text { numbers }\end{array}$ \\
\hline 1 & 0.6 & $2,6,10,14,17,21,28,30,34$ \\
\hline 2 & 0.75 & $\begin{array}{l}1,4,7,9,12,16,19,22,24,27,29,32 \\
, 35\end{array}$ \\
\hline 3 & 0.8 & $\begin{array}{l}3,5,8,11,13,15,18,20,23,26,31, \\
33,36\end{array}$ \\
\hline
\end{tabular}

Table 2 Loading data

\begin{tabular}{|l|l|l|l|}
\hline Feeder & $\begin{array}{l}\text { Average Load } \\
(\mathrm{MW})\end{array}$ & $\begin{array}{l}\text { Peak Load } \\
(\mathrm{MW})\end{array}$ & $\begin{array}{l}\text { Numbers of } \\
\text { customers }\end{array}$ \\
\hline 1 & 3.645 & 5.934 & 652 \\
\hline 2 & 2.15 & 3.5 & 2 \\
\hline 3 & 3.106 & 5.057 & 632 \\
\hline 4 & 3.39 & 5.509 & 622 \\
\hline Total & 12.291 & 20 & 1908 \\
\hline
\end{tabular}

The test system has four feeders and thirty six feeder sections. Feeder types and lengths are mentioned in Table 1. For calculation of indices, the failure of breaker and bus bar can be neglected because the failure ration is so small. The tie line effect is also neglected. The load data and system reliability data is shown in Table 2 and 3.

Table 3 Reliability and system data

\begin{tabular}{|l|l|l|l|l|}
\hline Component & $\lambda$ & $\mathrm{r}$ & $\mathrm{r}_{\mathrm{p}}$ & $\mathrm{s}$ \\
\hline $\begin{array}{l}33 / 11 \\
\text { Transformer }\end{array}$ & 0.015 & 200 & 15 & 1 \\
\hline $\begin{array}{l}11 / 0.4 \\
\text { Transformer }\end{array}$ & 0.015 & 200 & 10 & 1 \\
\hline $\begin{array}{l}11 \mathrm{kv} \\
\text { Lines }\end{array}$ & 0.065 & 5 & & 1 \\
\hline
\end{tabular}

The $\lambda$ is failure rate per year per kilometer for lines and failure rate per year for transformers. The $\mathbf{r}$ is repair time in hour. The $\mathbf{r}_{\mathbf{p}}$ is replacement time by a spare in hour. The $\mathbf{s}$ is switching time in hour. 


\section{SIMULATION RESULTS}

In automation system, the switching time is decreased $1 \mathrm{hr}$ to 1 minutes. Repaired time is also decreased 5 hours to 0.5 hour [3]. Assume that transformer replacing time is reduced 10 hours to 5 hours. By changing these data, reliability condition is analyzed in two cases as follows:

\section{Case I : Conventional System}

Case II: System with IoT Technology

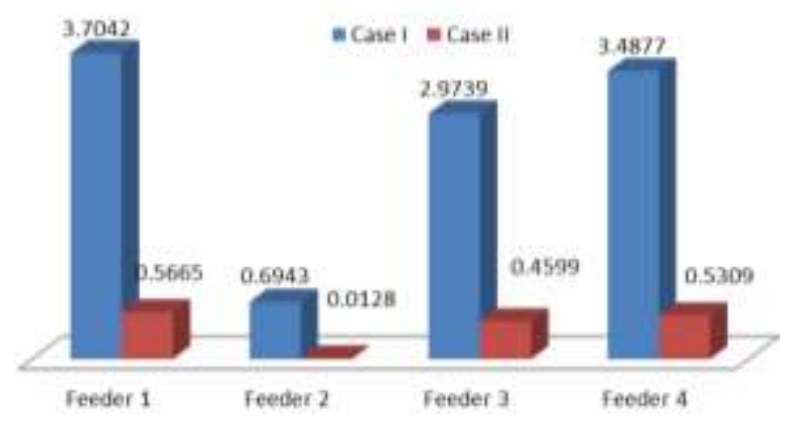

Fig.3 Comparison of ENS in two cases

The comparison of energy not supply is shown in Fig. 3 and the amount of ENS is compared in two cases for four feeders. according to results, the amount of ENS is reduced using IoT technology. For example, ENS is decreased from $3.7042 \mathrm{MW}$ to $0.5665 \mathrm{MW}$ per year.

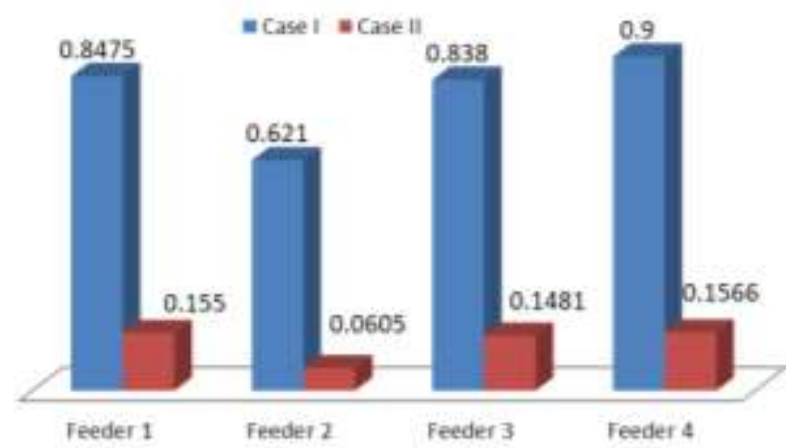

Fig.4 Comparison of SAIDI in two cases

In Fig.3, the c system average interruption duration index is compared for four feeders. As we can see in the result, the duration of interruption is decreased in case II. For feeder 1, the customer will be interrupted 0.8475 hours in one year if the system is the conventional system. After installation of IoT, the interruption time is reduced to 0.155 hour. This analysis is only for small test system and there will be a huge impact for a large

\section{CONCLUSION}

Or thanks to the experts who have contributed towards development of the template. According to the analytical results in this paper, the concentration of IoT can make the power system reliability better. of Things is improving efficiency to assist the smart grid system. By collecting and analyzing data, utilities are able to provide more reliable and efficient power to users. As the use of IoT technology becomes more prevalent, we can expect a greener and more efficient electricity delivery system.

\section{ACKNOWLEDGMENTS}

We are deeply grateful to Ministry of Education, Myanmar for giving a chance for motivating to submit the research papers.

\section{REFERENCES}

[1] GSM Association. (2014). Understanding the internet of thing (IoT). https://www.gsma.com/iot/wp-

content/uploads/2014/08/cl_iot_wp_07_14.pdf

[2] Electric Technology (2016). Internet of things and its application in electrical power industry

http://www.electricaltechnology.org/20 16/07/internet-ofthings-iot-and-its-applications-in-electrical-powerindustry.html

[3] Ohn Zin Lin and Hajime Miyauchi(2014). DG Potential in Myanmar and Proposed Method to Improve Distribution System Reliability by DGs and SCADA Based Distribution Automation System. Paper presented at the international conference of electrical engineering, 20145: HongKong

[4] Roy Billition and Ronald Allan (1984)."Reliability Evaluation of Power System", New York,

[5] Ronald Allan, Roy Billinton, I Sijarief, L.Goel and K.S.So (1991). A Reliability Test System for Educational Purpose-Basic Distribution System data and results. IEEE Trans. Power Syst, vol.6, no.2, pp.813-820, May 1991.

[6] U.S Department of Energy (2012). Reliability Improvements from the Application of Distribution Automation Technologies-Initial Result.

[7] Ohn Zin Lin, Hajime Miyauchi.(2017) "Reliability Forecasting in Distribution System Considering Variable Failure Rate: Combination of Equipment Inspection Method and Weibull Analysis", International Review of Electrical Engineering (IREE)

[8] Ohn Zin Lin, Hajime Miyauchi.(2017) "Optimal Replacement Time of Electrical Components Based on Constant-Interval Replacement Model: Equipment Inspection Method and Weibull Analysis", Energy and Power Engineering, 2017 